\title{
Designing a tool for service-dominant strategies using action design research
}

\author{
Egon Lüftenegger ${ }^{1} \cdot$ Marco Comuzzi $^{2}$ • \\ Paul W. P. J. Grefen ${ }^{1}$
}

Received: 10 October 2013/Accepted: 18 November 2015/Published online: 29 December 2015

(C) The Author(s) 2015. This article is published with open access at Springerlink.com

\begin{abstract}
Both academic research and industrial practice recognize difficulties in translating the principles of service-dominant (S-D) business logic into actionable insights for practitioners, particularly when considering S-D logic at the strategic level. To address this problem, this paper focuses on the conceptualization, formulation, and communication of an S-D business strategy. From the theoretical standpoint, we conceptualize the elements of an S-D strategy by filtering the scattered literature about S-D strategy and business models through the lenses of traditional views of business strategy. From the practical standpoint, we develop a tool embedding our conceptual development to support practitioners in the formulation and communication of S-D strategy. While traditional strategy tools take a value chain perspective, our tool helps to position the focal organization at the center of a complex ecosystem of partners who are cocreating value. Following the principles of action design research, the tool is developed and evaluated in close collaboration with practice in a case study in the financial services industry. Consequently, this paper contributes both to the conceptual and the practical operationalization of S-D logic at the strategic level.
\end{abstract}

Keywords Service-dominant business - Action design research - Management tool $\cdot$ Strategy

Marco Comuzzi

marco.comuzzi.1@city.ac.uk

Egon Lüftenegger

e.r.luftenegger@tue.nl

Paul W. P. J. Grefen

p.w.p.j.grefen@tue.nl

1 School of Industrial Engineering, Eindhoven University of Technology, P.O. Box 513,

5600 MB Eindhoven, The Netherlands

2 Department of Computer Science, City University London, Northampton Square,

London EC1V OHB, UK 


\section{Introduction}

The shift from goods-dominant (G-D) to service-dominant (S-D) business has been in process since the early 1990s, when the manufacturers' role of producing and selling products within the value chain started becoming less profitable (Wise and Baumgartner 1999). This transition has also been triggered by changes in demand: customers increasingly require fully fledged solutions for their needs. This forces companies to innovate toward service orientation as a survival strategy for their business. One example of this trend is Xerox, shifting from manufacturing and sales of copiers to provisioning complete enterprise document management solutions (Mont 2002).

While the traditional marketing approach pushes companies to think about how to produce, promote, and sell products at a particular price and place (McCarthy 1960), contemporary marketing scholars distinguish between a traditional and a new mindset: G-D logic and S-D logic (Lusch and Vargo 2008). The former focuses on the product and the manufacturer's value chain. The latter focuses on the value network and establishes the role of the product as a mechanism for service provision. In other words, according to S-D logic, value is not created by selling the product, but by the service delivered through the product.

G-D logic still represents the most widely adopted frame of reference to tackle practical issues in business design (Spohrer and Maglio 2008). In the academic literature, S-D logic has been extensively conceptualized by mainly marketing scholars, but its role in driving service business design and operation remains largely unexplored (Ostrom et al. 2010; Grönroos and Gummerus 2014). Specifically, while some approaches apply S-D logic to analyze ex-post the evolution of the dynamics of real world businesses (Kowalkowski 2011; Karpen et al. 2012; Skalen et al. 2014), a conceptualization of S-D logic is currently lacking for pretical use in business design. Consequently, academic literature calls for applied research to translate S-D logic into actionable insights for practice (Karpen et al. 2015; Huff and Möslein. 2009).

Since strategy is universally recognized as the first step in the practice of business design (Osterwalder and Pigneur 2002), the first step for an organization to drive the change toward service dominance is the formulation of an S-D business strategy. Hence, in this paper, we consider the following research question: How can we facilitate the conceptualization, formulation, and communication of a S-D strategy?

From the theoretical standpoint, we answer our research question by identifying and defining a structured set of elements that conceptually define an S-D strategy. This is achieved by analyzing the existing literature on S-D logic using the traditional approaches to strategy formulation as a conceptual bridge. From the practical standpoint, we develop a management tool for the formulation and communication of an S-D strategy, i.e., the S-D strategy canvas (S-DSC), which embeds our conceptual development of S-D strategy elements. The S-DSC is developed in close collaboration with practitioners. In particular, it embeds the feedback received by practitioners during an iterative development process and is 
evaluated in a practical scenario where executives are required to formulate an S-D strategy.

During the development and evaluation of the S-DSC, we have worked with a large international asset-based finance company (AssetFin ${ }^{1}$ ) and their car-leasing subsidiary (CarLease). In particular, the S-DSC is developed embedding the feedback received from strategy designers at AssetFin and evaluated by executives designing S-D strategies at CarLease formulating their own strategy. Both companies are clearly positioned in markets where S-D business innovation is required to overcome the threat posed by the global crisis of financial markets of the late 2000s and by the decline of traditional vendor-based asset leasing schemes.

As far as research methods are concerned, we adopt the action design research (ADR) paradigm (Sein et al. 2011). This research paradigm combines the benefits of design science research, i.e., to design an artifact solidly grounded in academic theory that solves a practical issue, and action research (AR), i.e., developing theory and tools through a strong mutual interaction of teams of academics and teams of practitioners.

This paper is structured as follows. In the next section, we give more detail about the research method that we have adopted and also discuss the case study selected for our research. We then review the literature on business strategy and S-D logic. Having discussed our theoretical conceptualization of S-D strategy, we discuss the iterative development of the S-DSC following the ADR approach. For each of the two iterations, we discuss the design process and the evaluation with practitioners. Finally, before presenting our conclusions, we discuss the lessons learned during the entire research process.

\section{Research method and case selection}

In this section, we first discuss the research method selected for our research and then provide more detail about our case study.

\subsection{Research method selection}

Our research aims to achieve the dual goal of creating academic knowledge and solving practitioners' problems. The first goal is addressed by the conceptualization of S-D strategy. The second goal is addressed by the development of the S-DSC, a novel tool (or artifact) to formulate and communicate S-D strategy.

To achieve our goals, we have to carefully select our research method. On the one hand, design science research (DSR) has emerged as a research method for developing artifacts grounded in academic theory. However, in DSR the involvement of end-users occurs only during evaluation, once the artifact is already fully developed (Hevner et al. 2004). On the other hand, AR (Coughlan and Coghlan 2002) is an iterative research method where researchers intervene in the real world

\footnotetext{
${ }^{1}$ For the sake of confidentiality, we use fictitious names for the companies involved in our research. More details on these firms are provided in the next section.
} 
to solve practitioners' problems and to gain scientific knowledge (Avison et al. 1999). AR always involves user participation in the creation of artifacts, while in DSR users may be assumed by the researcher during the design process (Peffers et al. 2006).

ADR (Sein et al. 2011) has recently emerged as a research method that combines AR and DSR to focus clearly on artifact development while taking into consideration user participation and feedback during the experimentation with different versions of the artifact. Specifically, ADR considers the artifact development and organizational impact at the same level, with artifacts shaped by the organizational context during development and use. As such, we have chosen ADR as the best suitable research method to fulfill the twofold objective of our research.

The ADR method (Sein et al. 2011) comprises an initial stage of problem formulation. After this initial stage, the theory and the artifact are iteratively developed. Each iteration includes a phase of building, intervention, and evaluation of the artifact, followed by a stage of reflection and learning from the intervention with the artifact in practical settings. Finally, the process ends with the formalization of learning, where researchers reflect on the entire theory and artifact development process.

\subsection{Case selection}

ADR requires close collaboration between academia and industry. Academics should be fully embedded in the industry context and contribute not only to research, but also to the achievement of solutions to practical problems. Therefore, the case study in ADR cannot simply be selected, but is defined by the opportunity of closely collaborating with industry partners facing the issues addressed by the research (Sein et al. 2011). In our specific case, the case study involved two organizations providing asset-based financing services, i.e., AssetFin and CarLease (more information about the two organizations is reported in Table 1). The collaboration between the researchers and the two organizations was established in

Table 1 AssetFin and CarLease

\begin{tabular}{|c|c|c|}
\hline & AssetFin & CarLease \\
\hline $\begin{array}{l}\text { Size- } \\
\text { employees/net } \\
\text { profit (2014) }\end{array}$ & 4900/400M EUR & 550/45 M EUR \\
\hline $\begin{array}{c}\text { Reach (no. of } \\
\text { countries) }\end{array}$ & 41 & 10 \\
\hline Industries & $\begin{array}{l}\text { Food, agriculture, health, construction, and } \\
\text { transportation }\end{array}$ & Automotive \\
\hline $\begin{array}{l}\text { Relation with } \\
\text { researchers }\end{array}$ & $\begin{array}{l}20 \% \text { working time spent by one researcher at } \\
\text { company's premises in } 2009-2013 \text {; monthly } \\
\text { plenary updates on research progress }\end{array}$ & $\begin{array}{l}\text { Monthly updates on research } \\
\text { progress; } 2 \text { plenary workshops for } \\
\text { tool validation }\end{array}$ \\
\hline $\begin{array}{l}\text { People involved } \\
\text { in the } \\
\text { research }\end{array}$ & $\begin{array}{l}\text { Practitioners team: } 1 \text { senior R\&D manager ( } 15 \\
\text { years experience) } 1 \text { junior R\&D manager ( } 5 \\
\text { yrs) }\end{array}$ & $\begin{array}{l}\text { Users team: } 9 \text { business unit } \\
\text { executives (average } 7.6 \text { years } \\
\text { experience) }\end{array}$ \\
\hline
\end{tabular}


2009 , with one member of the academic research team spending $20 \%$ of his time during the project at AssetFin's facilities in the corporate strategy division.

The organizational context of AssetFin and CarLease clearly fits the purpose of ADR for investigating the issue of S-D strategy conceptualization, formulation, and communication. AssetFin is a large provider of asset-based financing services with headquarters in Europe and offices in 41 countries worldwide. Initially targeted to the local community, in the past 30 years AssetFin's services have developed a global reach, while striving to maintain their local appeal. While AssetFin maintains profitable lines of business with its local and global customers, the management at AssetFin has also realized that competitiveness in the long term may become harder to sustain without innovative business models, stressing that traditional lines of business should be complemented by a recalibration of the company's offer based on the paradigm of S-D logic.

One particular case requiring the investigation of innovative S-D strategies is CarLease, i.e., AssetFin's car leasing subsidiary. The traditional business of CarLease, clearly focused on the leasing of the good (or asset), i.e., cars, should be complemented by innovative, S-D solutions. We observed, in fact, that in the current business model, CarLease makes a profit on the asset lifecycle with a high dependency on vendor partners, i.e., car manufacturers and dealers. However, vendor partners have been shifting from simply selling assets to delivering mobility solutions to customers. These changes in the value propositions of vendors' partners threaten the current vendor finance business model of CarLease, driven by a G-D, asset-driven strategy.

In the context of our case study, ADR requires the participation of three different teams, namely the researchers, the practitioners, and the users. The researchers and the practitioners collaborate toward the conceptual development and the tool design. The users participate in the evaluation of the tool. In our research (see Table 1), we, as the researchers, mostly collaborated directly with the managers of Global R\&D at AssetFin, i.e., the practitioners. The users are represented by executives of CarLease. Contact with this team was mainly in the form of workshops.

More precisely, the practitioners team comprised a senior R\&D Manager of AssetFin with 15 years experience in strategy and business model design in the financial sector and a junior R\&D Manager with 5 years experience in business design. The users team was constituted by a total of 9 executives in charge of different business units within CarLease with an average experience of 7.6 years in strategy definition and management.

Besides the time spent by one researcher at AssetFin's premises, we held regular meetings, at least monthly, with the practitioners at AssetFin to assess the progress of the research, such as conceptual and tool development, and decide course of action. The users team at CarLease was updated on a monthly basis on the progress of the research and was involved in two workshops for the testing and evaluation of the two versions of the S-DSC tool. More details about these workshops are discussed later in this paper after having discussed the design of the tool. 


\section{Related work on traditional and service-dominant approaches to strategy}

We first briefly review the related work on traditional approaches to strategy and go on to examine related research on S-D logic at the strategic level. The goal of this review is to analyze relevant traditional approaches to strategy, in order to adopt the appropriate jargon and perspectives while building a conceptual bridge between the traditional and the S-D views of strategy.

As far as traditional strategy is concerned, Hunt and Derozier (2004) distinguish between the business scholar and the marketing scholar approaches to the study of strategy. Business scholars identify the industry-, competence-, and resource-based approaches to strategy, whereas marketing scholars consider the market-oriented and relational marketing approaches. The rationales behind these approaches are summarized in Table 2.

Empirical research on S-D logic focuses mainly on the analysis of types of S-D value propositions (Kowalkowski 2011; Skalen et al. 2014). With regard to empirical studies, research on S-D logic only offers guidelines that are difficult to translate into a set of actionable business concepts to define S-D strategy. The few studies that focus on the transition from G-D to S-D logic in practice consider case studies analyzing ex-post how companies have implemented such a transition $(\mathrm{Ng}$ et al. 2012; Smith et al. 2014).

A preliminary effort to come up with a conceptual model to bridge S-D logic with business strategy design is presented by Karpen et al. (2012). Such a model, however, presents two main limitations. First, it only focuses on the definition of strategy as a set of capabilities of the organization, whereas traditional strategies include other perspectives, such as resource-based and relational marketing. Including more than one perspective becomes particularly relevant when aiming at

Table 2 Traditional approaches to strategy

\begin{tabular}{ll}
$\begin{array}{l}\text { Strategy } \\
\text { approach }\end{array}$ & Rationale \\
\hline Industry-based & $\begin{array}{c}\text { Strategic view suggests that, to achieve competitive advantage, firms should choose } \\
\text { the appropriate industry and select a generic strategic approach, such as cost } \\
\text { leadership or differentiation }\end{array}$ \\
$\begin{array}{c}\text { Resource-based } \\
\text { Strategic view suggests that, to achieve competitive advantage, firms should acquire } \\
\text { or develop resources that are valuable, rare, imperfectly mobile and non- } \\
\text { substitutable } \\
\text { Competence- } \\
\text { based }\end{array}$ & $\begin{array}{c}\text { Strategic view suggests that to achieve competitive advantage firms should identify, } \\
\text { develop, reinforce, maintain, and leverage distinctive competences }\end{array}$ \\
$\begin{array}{c}\text { Strategic view suggests that, to achieve competitive advantage, firms should gather } \\
\text { information on potential customers and competitors and share this information } \\
\text { across between business units to guide the strategy }\end{array}$ \\
$\begin{array}{c}\text { Strategic view suggests that, to achieve competitive advantage, firms should develop } \\
\text { a relationship portfolio with stakeholders such as customer, suppliers, employees, } \\
\text { marketing }\end{array}$ \\
\begin{tabular}{c} 
and competitors \\
\hline
\end{tabular}
\end{tabular}


overcoming the trap set by the traditional G-D view of strategy. Second, the identified strategic capabilities are not tested with practitioners formulating their own strategy, but only with illustrative examples.

As far as the use of S-D logic for defining and analyzing business strategy is concerned, we consider three main research articles (Lusch et al. 2007; Karpen et al. 2012; Järvesivu 2010). These are used as the theoretical foundation for our S-D strategy conceptualization and artifact development and are discussed in the remainder of this section. From these studies, we extract a set of 22 strategic statements, which are shown in Table 7 in the Appendix of this paper. The identified statements are classified based on their relation with the traditional strategic perspectives of business competences (BC), business resources (BR), and market relations.

Vargo and Lusch (2004) first attracted the interest of academia to S-D logic, though we consider (Lusch et al. 2007) as their most relevant paper in the context of S-D logic at a strategic level. Although the title of this research paper does not explicitly mention strategy, the authors aim to help companies gain a competitive advantage through S-D logic in the discussion of managerial implications of their work. The S-D strategy to achieve competitive advantage is formulated through a set of statements (see SS1-SS9 in Table 7). In a different paper (Lusch and Vargo. 2014), the same statements are embedded in a strategy appraisal tool. However, such a tool is not developed or even evaluated with practitioners and the authors do not provide a clear rationale of how the elements of the tool have been derived.

The second selected research work provides an explicit connection between S-D logic and traditional approaches to strategy, by defining strategic capabilities (Karpen et al. 2012). However, by focusing only on capabilities, such an approach does not integrate the S-D logic with the resource and relational marketing perspectives of strategy. Also in this case, the identified strategic capabilities (see statements SS10-SS15 in Table 7) have not been applied in practice, but only to illustrative examples. As such, they need further refinement before becoming usable by practitioners to formulate and communicate their own S-D strategy.

In the last selected research work, Järvesivu (2010) uses the S-D logic to elaborate an S-D strategy for a waste management start-up. This research is relevant because it is the first of its kind where the results have been applied to a real world case. However, the research ignores the two previously discussed papers on S-D logic at a strategic level and it fails, in particular, to consider the strategic capabilities perspective. Moreover, the article does not develop any sort of tool for strategy formulation or appraisal. Strategic statements in this study are expressed as a comparison between G-D logic and S-D logic concepts, e.g., "rigid versus flexible organizational boundaries." We have developed a set of S-D strategic statements from this research work by extracting the S-D dimension of each statement (see SS16-SS22 in Table 7).

The three identified sets of strategic statements complement each other. The first set (SS1-SS9) focuses mainly on the competences needed by a company to succeed in a market by adopting S-D logic. The second set of statements (SS10-SS15) complements the first one by considering different types of interactions that companies should support for developing an S-D strategy. Finally, the third set of 
statements (SS16-SS22) increases the practical relevance of the other two sets by including strategic statements developed within the context of a real world case study.

\section{Conceptualization of the service-dominant strategy}

Having analyzed the literature on the traditional and S-D approaches to strategy, our aim is to conceptualize the elements of an S-D strategy, that is, to identify a set of elements to drive the process of strategy formulation and communication.

Our theoretical framework is graphically represented in Fig. 1. It is based on the literature on traditional and S-D approaches to strategy formulation reviewed in the previous section and the theory of the dominant logic trap (Prahalad 2004). According to theory of the dominant logic trap, executives are often locked into management concepts and practices that have succeeded in the past for their organizations. This may reduce the organizational capability for innovation, hinder creativity, and prevent diversification and future success.

The funnel visualization of the dominant logic (Bettis and Prahalad 1995) of Fig. 1 clarifies how the dominant logic trap applies in our context and how it can be overcome. Elements related to traditional approaches to strategy are used to create a bridge between the G-D strategic mindset of an organization, i.e., the dominant logic, and the S-D mindset. This bridge will let the S-D Strategy perspective pervade the current mindset of the organization, superseding the current dominant logic.

Thanks to our theoretical framework, we are able to achieve the dual contribution envisioned by ADR. From the theoretical point of view, we identify a new structured set of concepts describing an S-D strategy. This new set of concepts is integrated, as it brings together current contributions in the literature about S-D logic at the strategic level, and is easier to adopt in practice, as it is based on the traditional approaches to strategy to overcome the dominant logic trap. From the practical point of view, we develop a management tool embedding the results of our

Service dominant business concepts

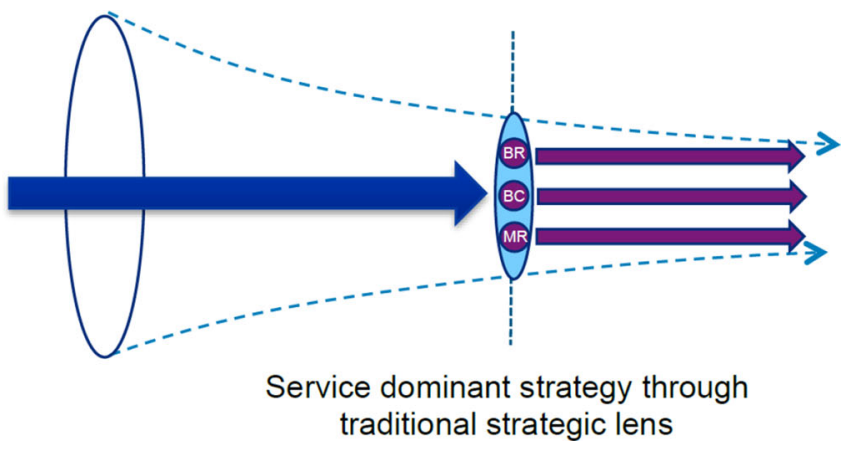

Fig. 1 Illustration of the conceptual framework 
theoretical conceptualization, that is, the S-DSC to formulate and communicate S-D strategies.

Before integrating the literature about S-D strategy to identify the S-D strategy conceptual elements, we need to identify the traditional approaches to strategy that we use to establish our conceptual bridge. As shown in Fig. 1, we consider only the traditional approaches to strategy related to BR, BC, and market relationships (MR). We did not find a relation between the S-D strategic statements and the industrybased strategy approach because fundamental elements of this traditional approach to strategy, such as cost leadership, differentiation, or focus, do not find a counterpart in the S-D strategic statements of Table 7 in the Appendix. Excluding the industry-based strategy is consistent with other research stating that Porter's competitive advantage strategy and its value chain approach are more suitable for the manufacturing industry rather than the service industry (Stabell and Fjeldstad 1998). The market-oriented strategy is also not considered at this stage. According to S-D logic, interaction with the customer must be on an individual basis instead of directed to a whole market segment at once, since co-production is enacted with individual customers to let them perceive value in a unique way. This result is validated by the S-D logic literature, which predicates a shift from "marketing to" the customer toward "marketing with" the customer (Lusch et al. 2007).

We identify the elements of an S-D strategy by matching the strategic statements identified in Table 7 with the conceptual bridge established in Fig. 1. The process followed by us, as the team of researchers, and the practitioners to jointly identify the elements of an S-D strategy is shown in Fig. 2. By design, each S-D strategic statement is matched against each traditional strategic category, i.e., market relationships, $\mathrm{BC}$, and $\mathrm{BR}$. If an $\mathrm{S}-\mathrm{D}$ strategic statement fits multiple categories, then it is dissected into each matching category. The outcome of the process is a strategic element for each matching category identified for each S-D strategic statement.

The process depicted in Fig. 2 has been enacted jointly by the teams of researchers and practitioners using a simplified version of the Delphi method (Okoli and Pawlowski 2004). First one practitioner and the researchers executed the matching process of Fig. 2. The output of this exercise is presented to the second practitioner for validation and enrichment. Finally, consensus on the strategic elements is obtained in an open brainstorming session involving both teams of researchers and practitioners. Tables 3, 4, and 5 show the outcome of this process for the strategic statements SS1-SS9 (Lusch et al. 2007), SS10-SS15 (Karpen et al. 2012), and SS16-SS22 (Järvesivu 2010), respectively.

Starting from the outcome reported in Tables 3, 4, and 5, the final set of conceptual elements of the S-D strategy is obtained by applying a homogenization process to avoid label and concept redundancy or overlap. For each S-D strategic element, we specify (in parentheses) which S-D strategic statement it is derived from and the rationale behind homogenization, if needed.

As far as Market relationships are concerned, we identify the following homogenized S-D strategic elements:

Contextually individuated The elements "individuated interaction"(from SS10) and "contextual" (from SS22) are homogenized into the element "contextually 


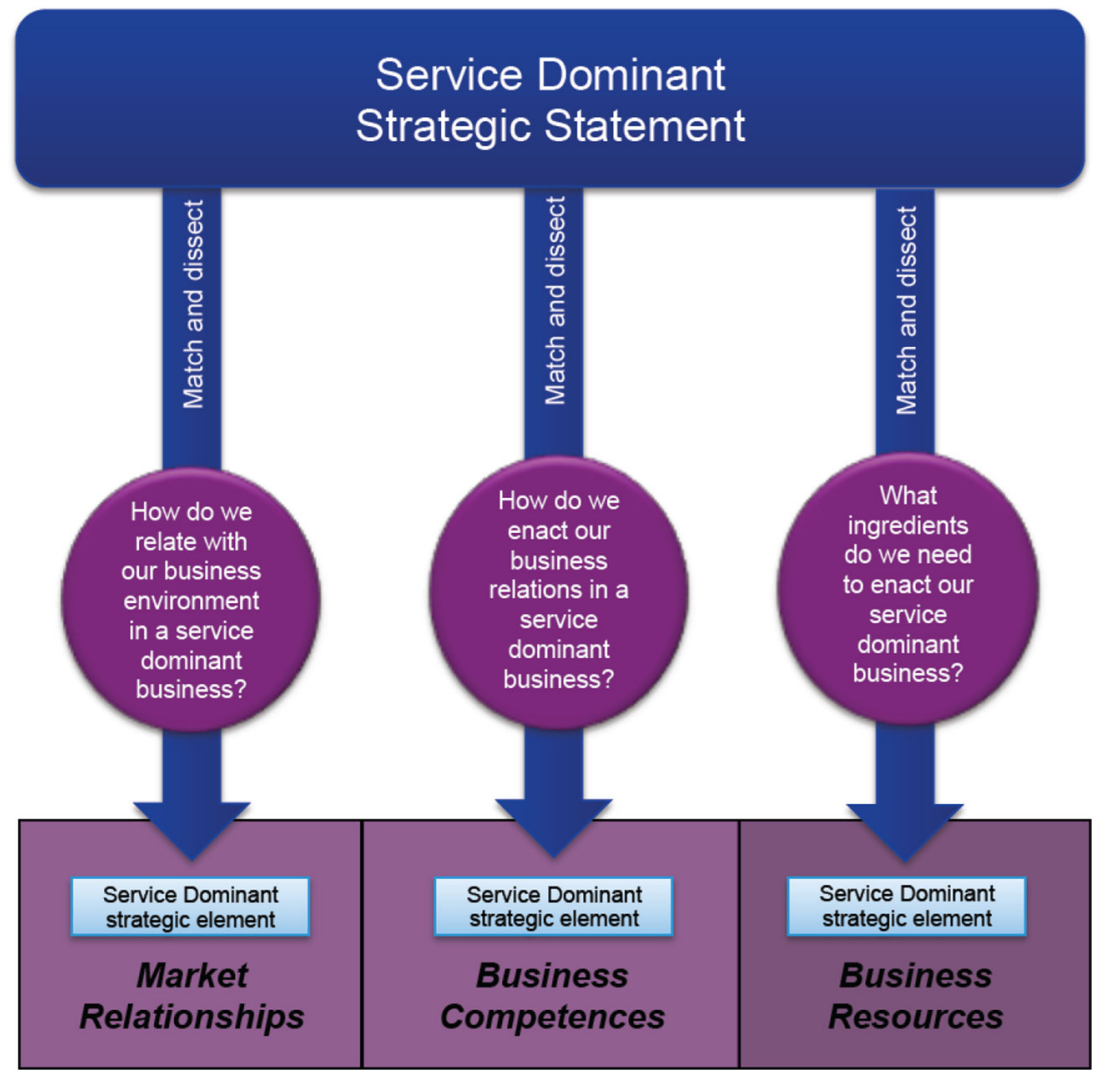

Fig. 2 Identification process of the service-dominant strategy elements

individuated." The concept behind this element is that value is contextual to each specific party in a value network (value-in-context) rather than an arbitrary value.

Empowerment The element "empowered interaction" (from SS13) is relabeled "empowerment" to align it with the naming of the other elements in this strategic category. The empowerment element acknowledges the active role of the customers in the co-production of services. The firm should facilitate this active role by considering customer input in the development of their core offering (Karpen and Bove 2008).

Ethical mutual benefit The elements "ethical interaction" (from SS12) and "mutual benefit" (from SS19) are integrated and homogenized into the element "ethical mutual benefit," signifying that the benefit from the interaction between the parties in the value network should be mutual. Moreover, the increasing transparency in market interactions requires ethical behavior that benefits the parties involved (Karpen and Bove 2008).

Flexible organizational boundaries The element "flexible organizational boundaries" (from SS16) establishes that collaboration between firms is enabled 
Table 3 Matching of service-dominant strategic statements 1-9 from (Lusch et al. 2007)

\begin{tabular}{|c|c|c|c|}
\hline Service-dominant strategic statement (SS) & $\begin{array}{l}\text { Market } \\
\text { relationships }\end{array}$ & $\begin{array}{l}\text { Business } \\
\text { competences }\end{array}$ & $\begin{array}{l}\text { Business } \\
\text { resources }\end{array}$ \\
\hline $\begin{array}{l}\text { SS1 - "competitive advantage is a function of how } \\
\text { one firm applies its operant resources to meet the } \\
\text { needs of the customer relative to how another firm } \\
\text { applies its operant resources" }\end{array}$ & & $\begin{array}{l}\text { Meet customer } \\
\text { needs }\end{array}$ & Operant \\
\hline $\begin{array}{l}\text { SS2 - "collaborative competence is a primary } \\
\text { determinant of a firms acquiring the knowledge for } \\
\text { competitive advantage" }\end{array}$ & & Collaboration & \\
\hline $\begin{array}{l}\text { SS3_- "the continued ascendance of information } \\
\text { technology with associated decrease in } \\
\text { communication and computation costs, provides } \\
\text { firms opportunities for increased competitive } \\
\text { advantage through innovative collaboration" }\end{array}$ & & Collaboration & $\begin{array}{l}\text { Information } \\
\text { technologies }\end{array}$ \\
\hline $\begin{array}{l}\text { SS4_ "firms gain competitive advantage by engaging } \\
\text { customers and value network partners in co-creation } \\
\text { and co-production activities" }\end{array}$ & & $\begin{array}{r}\text { Co-creation and } \\
\text { co-production }\end{array}$ & $\begin{array}{l}\text { Customers } \\
\text { and partners }\end{array}$ \\
\hline $\begin{array}{l}\text { SS5- "understanding how the customer uniquely } \\
\text { integrates and experiences service-related resources } \\
\text { (both private and public) is a source of competitive } \\
\text { advantage through innovation" }\end{array}$ & & $\begin{array}{l}\text { Customer } \\
\text { understanding }\end{array}$ & Customer \\
\hline $\begin{array}{l}\text { SS6- "providing service co-production opportunities } \\
\text { and resources consistent with the customer's desire } \\
\text { level of involvement leads to improve competitive } \\
\text { advantage through enhanced customer experience" }\end{array}$ & & Co-production & \\
\hline $\begin{array}{l}\text { SS7- "firms can compete more effectively through } \\
\text { the adoption of collaboratively developed, risk- } \\
\text { based pricing value propositions. Appropriately } \\
\text { shifting the economic risk of either firm or customer } \\
\text { through co-created value propositions increase } \\
\text { competitive advantage" }\end{array}$ & & $\begin{array}{l}\text { Risk-based } \\
\text { pricing }\end{array}$ & $\begin{array}{l}\text { Value } \\
\text { propositions }\end{array}$ \\
\hline $\begin{array}{l}\text { SS8- "the value network member that is the prime } \\
\text { integrator is in a stronger competitive position. The } \\
\text { retailer is generally in the best position to become } \\
\text { prime integrator" }\end{array}$ & & $\begin{array}{l}\text { Resource } \\
\text { integration }\end{array}$ & $\begin{array}{l}\text { Value } \\
\text { network }\end{array}$ \\
\hline $\begin{array}{l}\text { SS9- "firms that treat their employees as operant } \\
\text { resources will be able to develop more innovative } \\
\text { knowledge and skills and thus gain competitive } \\
\text { advantage" }\end{array}$ & & & Employees \\
\hline
\end{tabular}

by a flexible border relationship, which is required to minimize the barriers between firms to collaborate in service co-production.

Bidirectional The elements "relational interaction" (from SS11) and "market dialog" are merged into the element "bidirectional" (from SS20). This is because both original research pieces use these elements to describe a two-way communication dialog between the firm and the customer.

As far as Business competences are concerned, we identify the following homogenized elements of an S-D strategy: 
Table 4 Matching of service-dominant strategic statements 10-15 from (Karpen et al. 2012)

\begin{tabular}{|c|c|c|c|}
\hline Service-dominant strategic statement (SS) & $\begin{array}{l}\text { Market } \\
\text { relationships }\end{array}$ & $\begin{array}{l}\text { Business } \\
\text { competences }\end{array}$ & $\begin{array}{l}\text { Business } \\
\text { resources }\end{array}$ \\
\hline $\begin{array}{l}\text { SS10_- "individuated interaction capability- } \\
\text { understanding individual customers' service } \\
\text { processes, contexts, and desired outcomes" }\end{array}$ & $\begin{array}{l}\text { Inidvidual } \\
\text { interaction }\end{array}$ & Understanding & Customers \\
\hline $\begin{array}{l}\text { SS11- "relational interaction capability-enhancing } \\
\text { the connection of social and emotional links with } \\
\text { customers in service processes" }\end{array}$ & $\begin{array}{l}\text { Relational } \\
\text { interaction }\end{array}$ & \multirow[t]{4}{*}{ Connection } & \multirow[t]{2}{*}{$\begin{array}{l}\text { Social and } \\
\text { emotiona }\end{array}$} \\
\hline $\begin{array}{l}\text { SS12_- "ethical interaction capability-supporting fair } \\
\text { and non opportunistic customer service processes" }\end{array}$ & $\begin{array}{l}\text { Ethical } \\
\text { interaction }\end{array}$ & & \\
\hline $\begin{array}{l}\text { SS13- "empowered interaction capability-enabling } \\
\text { customers to shape the nature and content of service } \\
\text { processes" }\end{array}$ & $\begin{array}{l}\text { Empowered } \\
\text { interaction }\end{array}$ & & \multirow[t]{2}{*}{ Content } \\
\hline $\begin{array}{l}\text { SS14_ “developmental interaction capability- } \\
\text { assisting customers' own knowledge and } \\
\text { competence development in service processes" }\end{array}$ & $\begin{array}{l}\text { Developmental } \\
\text { interaction }\end{array}$ & & \\
\hline $\begin{array}{l}\text { SS15-“concerted interaction capability-facilitating } \\
\text { coordinated and integrated service processes that } \\
\text { include customers" }\end{array}$ & & $\begin{array}{l}\text { Service } \\
\text { coordination }\end{array}$ & $\begin{array}{r}\text { Service } \\
\text { flows }\end{array}$ \\
\hline
\end{tabular}

Table 5 Matching of service-dominant strategic statements 16-22 from (Järvesivu 2010)

\begin{tabular}{|c|c|c|c|}
\hline Service-dominant strategic statement (SS) & $\begin{array}{l}\text { Market } \\
\text { relationships }\end{array}$ & $\begin{array}{l}\text { Business } \\
\text { competences }\end{array}$ & $\begin{array}{l}\text { Business } \\
\text { resources }\end{array}$ \\
\hline $\begin{array}{l}\text { SS16- "flexible organizational boundaries in which } \\
\text { collaboration is encouraged by minimizing the } \\
\text { barriers for building large networks of individuals } \\
\text { and organizations across boundaries" }\end{array}$ & $\begin{array}{l}\text { Flexible } \\
\text { organizational } \\
\text { boundaries }\end{array}$ & & $\begin{array}{l}\text { Large } \\
\text { networks }\end{array}$ \\
\hline $\begin{array}{l}\text { SS17- "networked resource integration by forming } \\
\text { and maintaining strategic partnerships that require } \\
\text { the integration of resources among all the actors } \\
\text { involved" }\end{array}$ & $\begin{array}{l}\text { Strategic } \\
\text { partnership }\end{array}$ & $\begin{array}{l}\text { Networked } \\
\text { resource } \\
\text { integration }\end{array}$ & Actors \\
\hline $\begin{array}{l}\text { SS18- "value with end customers in which the } \\
\text { company and customers co-develop offerings" }\end{array}$ & & $\begin{array}{l}\text { Co- } \\
\text { development }\end{array}$ & \\
\hline $\begin{array}{l}\text { SS19- "focus on value creating with the objective } \\
\text { of mutual benefits" }\end{array}$ & Mutual benefit & & \\
\hline $\begin{array}{l}\text { SS20_- A dialog between the company and the } \\
\text { market, where the innovation meets demand" }\end{array}$ & Market dialog & & \\
\hline $\begin{array}{l}\text { SS21- "market and customer knowledge is shared } \\
\text { and applied across all the organization rather than } \\
\text { a dedicated market function" }\end{array}$ & & $\begin{array}{l}\text { Market and } \\
\text { customer } \\
\text { knowledge }\end{array}$ & \\
\hline $\begin{array}{l}\text { SS22_ "holistic offerings that are part of the usage } \\
\text { context, where actors co-develop offerings and co- } \\
\text { create value" }\end{array}$ & Contextual & & \\
\hline
\end{tabular}

Service integration The elements "resource integrator" (from SS8), "networked integration" (from SS17), and "concerted interaction" (form SS17) are homogenized into the element "service integration." All three elements, in fact, point 
toward the integration of parties in an ecosystem using services (Lusch and Vargo 2008).

Co-production The elements "co-production" (from SS4 and SS6) and "codevelopment" (from SS18) are homogenized under the element "co-production," because they simply communicate the same concept under different labels, that is, including partners and the customer in the creation of service offerings as a key competence of the S-D strategy.

Knowledge sharing The elements "customer understanding" (from SS5), "developmental interaction" (from SS14), and "market and customer knowledge" (from SS21) are integrated into the element "knowledge sharing." This merge is performed to avoid repetition from the three literature sources and to provide an integrated view of the role of knowledge from different stakeholders in the S-D strategy. As discussed by Lusch et al. (2007), knowledge is captured by partners and the firm's employees to obtain customer insights for service enhancement. Järvesivu (2010) stresses that market and customer knowledge should be shared internally, while Karpen et al. (2012) stress that expertise and knowledge should be openly shared with the firm's partners and the customer.

Co-creation The element "co-creation" (from SS4) changes the traditional perspective where value is created by the firm and destroyed by the customer. Moreover, value co-creation with the customer is achieved in-use, by meeting customer needs as value-in-use. The value co-created in-use occurs in the form of service, rather than ownership of a good. Note that in our study, "co-creation" identifies value-in-use, while "co-production" identifies a collaborative way of service creation. The same terms have been used interchangeably by other authors in the literature.

Risk-based pricing The element "risk-based pricing" (from SS7) is included in the S-D strategy to stress the need for collaboration in a networked environment. The pricing mechanism should be based on the risk analysis of the actors that are co-producing the offering.

We do not include the element "collaborative" (from SS2) as a specific business competence element, because the collaborative approach is conceived as a metacompetence of S-D logic (Lusch and Vargo 2008). We can observe this collaborative approach in the element "co-production," which emphasizes the inclusion of partners and the customer in this process.

As far as Business resources are concerned, we identify the following homogenized elements of an S-D business strategy:

Information technologies The element "information technologies" (from SS3) is presented by Lusch et al. (2007) as an enabler to collaborate and integrate services.

Service flows The element "service flows" (from SS9) enables the shift from goods to services, where goods become the mechanism for service provision and customers buy a service flow rather than a tangible good (Lusch and Vargo 2008). The process orientation of the S-D logic is supported by this element, as service flows act as cross-organizational business processes to enable collaboration and service co-production (Karpen and Bove 2008). 
Employees The element "employees" (from SS9) is included in the S-D strategic statements as a source of customer knowledge and understanding (Lusch et al. 2007). Employees can learn about the customer preferences, which leads to a better understanding of the customer needs.

Customer The element "customer" (from SS5) is included in the singular form rather than plural (i.e., customers). Including the customer as a resource highlights the active role of the customer as producer-consumer in co-production. Moreover, customer involvement allows gathering knowledge about customers' needs and preferences in an active manner (Lusch et al. 2007).

Partners The element "partners" (from SS5) is identified as a key enabler for the firm to gain competitive advantage. Furthermore, the firm should engage partners in the value network in co-creation and co-production activities (Lusch et al. 2007).

The element "operant resource" is a resource class rather than an element in its own right. As defined in S-D logic, an operant resource is a resource capable of acting on other resources. Hence, we do not retain this element in our S-D strategy conceptualization.

\section{Tool development: Alpha version of the S-DSC}

Having conceptualized the elements of an S-D strategy in the previous section, we now describe how such a conceptualization is embedded in a tool for the formulation and communication of S-D strategy, i.e., the S-D strategy canvas (SDSC).

There are different approaches to strategy formulation. Mintzberg (1987) identifies the five Ps of strategy, where the strategy can be seen as a plan, a ploy, a perspective, a pattern, or a position. In our study, we focus on the perspective and position views of strategy. These two views, in fact, are able to drive the design of a tool to formulate and communicate a strategy. We argue that the plan, ploy, and pattern views of strategy are captured by the output of the utilization of our tool in a given organizational context and, therefore, should not be used to design the tool itself.

For the Alpha version of the S-DSC, we consider the strategy as a perspective approach. A perspective captures the way strategists perceive the world and the role of their focal company within it. This view is usually developed within the grounds of a dominant logic (Prahalad 2004), which should be the driver of strategy formulation.

We first discuss the design of the Alpha version of the S-DSC and, subsequently, we present the results of the intervention with the team of users using the Alpha S-DSC to formulate and communicate an S-D strategy.

\subsection{Design of the Alpha version of the S-DSC}

We use a canvas approach for developing our artifact. The canvas approach was introduced by the "business model canvas" (BMC) developed by Osterwalder and Pigneur (2010) as a visual method for supporting the design of business models. 
Although focused on the generation of more operational business models, the BMC tool is also commonly used in strategic management brainstorming exercises (Fritscher and Pigneur 2009). As such, the BMC has been also used in the past by the users at CarLease involved in our research. However, preliminary discussions with both teams of practitioners and users have highlighted the unsuitability of the BMC to drive the strategy process in an S-D context. The BMC clearly embeds a value chain, rather than a value network perspective over business design, identifying suppliers, and clients at different ends of the value chain and their role in generating costs and revenues for the focal organization. Many of the concepts identified by our conceptual development, such as co-creation, flexible organizational boundaries, or service integration, cannot simply be mapped onto the elements identified by the BMC tool.

We adopt the canvas visual representation for two main reasons. First, it has successfully been used to engage people in industry, from high-level executives to entrepreneurs, working in an interactive exercise. Second, the canvas approach is suited to communicating the conceptualization of a given business entity in a visual way, i.e., a business model, or, as in our specific case, an S-D strategy.

We discard more traditional tools to facilitate strategy formulation, such as Porter's five forces represented by five boxes and arrows or Porter's three generic strategies, represented by a matrix (Porter 1985). These traditional tools with a simple structure do not fit our purpose due to the high number of concepts identified in our theory development, which are likely to be reflected in the tool under design.

The Alpha version of the S-DSC is shown in Fig. 3. The canvas structure is defined by categories, subcategories, and conceptual elements. In total, the Alpha version includes three categories, six subcategories, and fifteen elements.

The categories, i.e., Market Relationships, BC, and BR, are those identified by our theoretical framework in Fig. 1. Each category is further divided into subcategories to facilitate the understanding of the strategic elements. For each category, in particular, we distinguish between pairs of complementary subcategories. The first one, Endogenous and Exogenous market relationships, is established by subclustering the market relationship elements with respect to their inside-out or outside-in nature in relation to the focal organization.

The elements Contextually individuated and Empowerment are market relationships starting from inside the company and directed toward the outside world. These two elements require the establishment of a relationship from the focal company to the actors involved in the S-D business. The market relationship elements to be established in the outside world are bidirectional, ethical mutual benefit, and flexible borders. These three elements in fact require, the establishment of a market relationship between at least a pair of actors.

The second pair of subcategories, i.e., value and collaboration $\mathrm{BC}$, is established by subclustering the BC elements. Co-creation and Risk-based pricing are the value elements that we propose from the value-in-use and the pricing perspectives. The Co-production, service integration and knowledge sharing are competences that the focal company needs to develop for the enactment of an S-D business.

The third pair of subcategories, i.e., the Actors and Infrastructures BR, is established by subclustering the BR elements associated with human resources and 


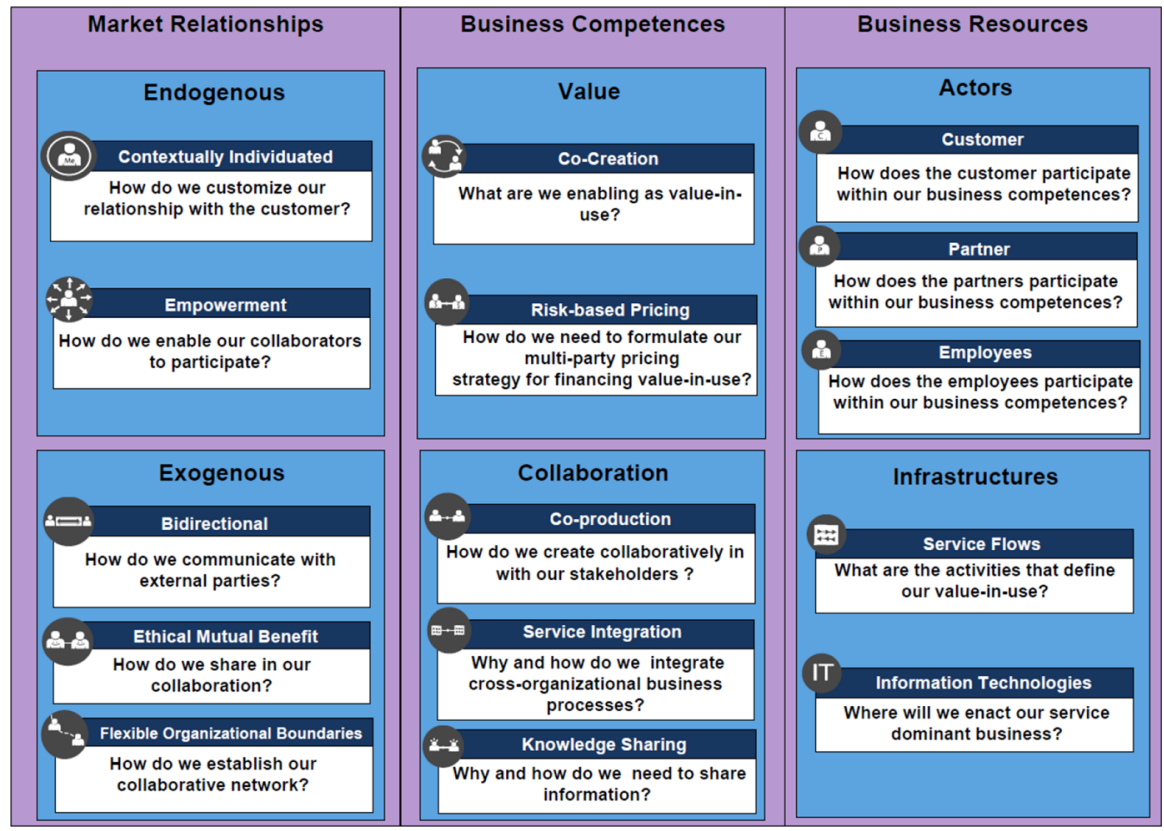

Fig. 3 Alpha version of the S-DSC: S-D strategy elements and associated questions

nonhuman BR, respectively. The human BR identified are Customer, Partners, and Employees. The nonhuman resources are included in the Infrastructures subcategory. Here, we consider the Information Technologies and Service Flows elements, remaining consistent with the previously mentioned homogenization.

While the elements of the S-DSC can be used for communicating an S-D strategy, the questions associated with each element are added to further guide the strategy formulation process.

\subsection{Evaluation of the Alpha version of the S-DSC}

The evaluation of the Alpha S-DSC was carried out in a working session with a team of users consisting of two innovation executives at CarLease. The goal of this session was twofold. For the users, the goal was to formulate an S-D strategy using the S-DSC. For us, the goal was to capture the shortcomings of the Alpha version of the S-DSC without any bias from the development team (researchers and practitioners). In capturing the shortcomings, the focus was on the understandability and applicability of the S-DSC artifact.

First, we presented the Alpha S-DSC to the users using a well-known highly S-D example scenario in the on-line music streaming industry (explanation session). Then, we asked the users to design an S-D strategy for their company using the S-DSC (strategy formulation session). Both sessions were facilitated by one practitioner and one researcher. 
Overall, working with the S-DSC was welcomed by users. The two executives stressed the suitability of the tool to think of strategy in terms of value networks and co-creation, instead of a linear value chain involving well-defined suppliers and customers. They started to think of car leasing as a mobility means, rather than the end goal. One of the executives, in particular, defined the value-in-use as enabling people "to be in the right place, at the right time" by offering a "seamless experience" in mobility. Using the S-DSC, the users were able to shift their thinking to the perspective of S-D logic, where the car is just one possible mechanism for mobility provision. The S-DSC enabled the users to think about the role of customers as active participants in the value co-creation, for instance "sharing mobility recommendations, based on their locations and mobility means preferences."

For evaluation we collected two types of evidence in the working session, i.e., a survey and the S-DSC filled in by the users. We classified ex-post the feedback received by users using four aspects: bridging, complexity, understandability, and Applicability. While the first aspect is specific to the objective of our study, i.e., facilitating the shift to the S-D strategy, the other three are common aspects for evaluating the quality of information in an organization (Batini et al. 2009).

Specifically, the survey contained items to evaluate the complexity and understandability of the elements in the canvas and their usability to establish a bridge between S-D logic and traditional approaches to strategy. The S-DSC filled in by the users was helpful to understand the applicability of its elements, i.e., to assess whether specific elements of the S-DSC had been actually used by the users while formulating their own S-D strategy.

The results of the intervention are discussed in the remainder of this section.

The bridging aspect relates to the use of traditional approaches to strategy to communicate the S-D strategy. We observed that the conceptual bridge was required for communicating the meaning of S-D strategy elements to the users. However, this bridge became less relevant for the strategy formulation exercise. The conceptual bridge was required only at the initial stage, and it was abandoned by the users after the explanation of the S-DSC and their understanding of the S-D Strategy perspective.

The complexity aspect relates to the number of elements of the tool. The Alpha artifact comprises a total of 24 concepts ( 3 categories, 6 subcategories, and 15 elements) that users need to understand before designing an S-D strategy. Our survey showed that 24 concepts is a very high number of concepts, requiring a timeconsuming (1-h) session only to explain their meaning. Therefore, a significant reduction of the number of concepts was highly desirable to engage users in strategy design.

Table 6 presents the evaluation of each concept in the Alpha S-DSC with regard to the aspects of understandability and applicability.

The understandability and applicability aspects were evaluated with the values high, medium, and low. The understandability criterion was evaluated during the explanation session and is considered high if the users did not ask for any clarification during the explanation of the element; medium if users sought clarification during the explanation session and declared that the clarifications given 
Table 6 Evaluation of understandability and applicability for the concepts of the Alpha S-DSC

\begin{tabular}{|c|c|c|c|}
\hline Type & Name & Understandability & Applicability \\
\hline Main category & Business competences & High & Low \\
\hline Main category & Business resources & High & Low \\
\hline Main category & Market relationships & High & Low \\
\hline Subcategory & Endogeneous & Low & Low \\
\hline Subcategory & Exogenous & Low & Low \\
\hline Subcategory & Value & High & High \\
\hline Subcategory & Collaboration & High & Low \\
\hline Subcategory & Actors & High & High \\
\hline Element & Infrastructures & High & Low \\
\hline Element & Co-creation & Medium & Low \\
\hline Element & Risk-based pricing & Medium & Low \\
\hline Element & Co-production & Low & Low \\
\hline Element & Service integration & High & Medium \\
\hline Element & Knowledge sharing & High & Low \\
\hline Element & Contextually individuated & High & Low \\
\hline Element & Bidirectional & Medium & Low \\
\hline Element & Ethical mutual benefit & Low & Low \\
\hline Element & Flexible organizational boundaries & Medium & High \\
\hline Element & Customer & Medium & Medium \\
\hline Element & Employees & Medium & Low \\
\hline Element & Service flows & Medium & High \\
\hline Element & Information technologies & High & Low \\
\hline
\end{tabular}

were sufficient to understand the concept and low if after clarifications during the explanation session the users still raised concerns about not being able to understand the meaning of the element. The applicability criterion was evaluated during the strategy formulation session. It is deemed to be high if the users were able to fill in the canvas in a way that is aligned with the meaning as intended by the researchers; medium if the users filled in the element during their strategy formulation, but in a way not aligned with the meaning intended by the researchers; and low if the users were unable to fill in the concept in the canvas during their strategy formulation.

The key insights obtained from the evaluation are:

1. The main categories work as a conceptual bridge. However, their applicability in S-D strategy formulation with users is low.

2. Subcategories are an overloading factor for users. They increase the complexity and decrease the understandability of the canvas. One example of overloading subcategories is Endogenous and Exogenous. The labels chosen for these subcategories were too grounded in academic literature for the users. This 
prevented the users from fully understanding the role of these subcategories within the S-D strategy formulation process.

3. Service flows is a concept with medium understandability and high applicability. The users were in fact able to answer the associated question, but the label chosen for the concept was still too operational for the users.

4. Only after the users understood the value-in-use concept (captured by the Value subcategory) was it possible for them to work on the remaining elements.

5. The element $\mathrm{Co}$-creation was an eye-opener for the users within the aim of designing an S-D strategy. This element has high applicability, because it shifts the mindset from the focus on the good-for example, cars-to the service that it renders-for example, mobility. To make this element more explicit and relevant to our canvas, while also reducing the number of categories, it was suggested we use the Value-in-use label instead of Co-creation.

As a summary from the intervention of the Alpha S-DSC with users, we can reflect the following:

1. The Alpha artifact helps shifting the mindset of executives from G-D logic toward S-D logic. Users were in fact able to design an S-D Strategy using at least 9 of the total 15 elements of the S-DSC.

2. The BC, BR, and market relationships categories were key in the building process of the Alpha S-DSC and are important to explain S-D Strategy perspective to practitioners. However, the main categories offer limited guidance to the users during the strategy formulation process.

3. The second iteration of the S-DSC should use the label Value-in-use instead of Co-creation. Co-creation was in fact confused by many users with Coproduction.

4. Value-in-use is the most important concept of the Alpha S-DSC. Hence, it should be emphasized more in the S-DSC. This can be achieved by clearly placing it at the top of the S-DSC to better guide the mindset shift toward the S-D logic.

5. The label Co-production may be interpreted as a concept too much related with manufacturing and, therefore, G-D logic. To avoid references to the G-D logic, the $C o$-creation label should be used instead of $C o$-production.

6. Both practitioners and users like to think of strategy as a position of the focal company rather than as a perspective. Hence, the focal company for which the S-D strategy is designed should explicitly appear in the S-DSC.

7. Elements such as Risk-based pricing and Ethical mutual benefit are too specific for strategy formulation. Moreover, before formulating questions associated with these elements, a stronger link to the business model concept should be devised. This link can be made by focusing on the value proposition and the customer. However, this also requires to adapt these traditional elements to the conceptualization of the S-D strategy. 


\section{Tool development: Beta version of the S-DSC}

In this section, we first present the building process of the Beta version of the $\mathrm{S}$-DSC addressing the feedback received during the evaluation of the Alpha version. Then we focus on the intervention with users using the Beta S-DSC.

\subsection{Design of the Beta version of the S-DSC}

The feedback received from users in the evaluation of the Alpha S-DSC can be summarized into two main points:

- The S-DSC should allow the design of S-D strategy as a position, that is, it should emphasize the role of the focal company in the strategy. The bridge toward concepts that are well-known to users while developing strategy to support the shift to S-D logic should therefore be redefined;

- Several mandatory amendments regarding concepts to be emphasized, dropped, and/or relabeled, should be addressed in the Beta S-DSC in order to improve its applicability and understandability, and to decrease its complexity.

To address the first point presented above, in particular, the Beta S-DSC must allow users to explicitly position their focal organization while formulating an S-D strategy. This renewed conceptual bridge supports managers in designing an S-D strategy using a strategic view that is in their current mindset, while the other concepts in the artifact push them toward designing a proper S-D strategy.

Theoretically, the strategy as a positional view deviates from the spirit of S-D logic, since it emphasizes the role of the focal company, downplaying the role of the network of partners to create value-added services for customers. However, in the dual objective of developing theory and solving real problems, artifact development in the ADR method predicates accommodating the practitioners' requirements that may prevent the full exploitation of the artifact if not implemented (Sein et al. 2011). Our choice represents a typical instance of such a case, because users were confused by the Alpha S-DSC as they were not able to position their own company on the canvas while developing their S-D strategy.

The Beta version of the S-DSC is shown in Fig. 4.

In terms of complexity, the Beta S-DSC considers only a two-level hierarchy of concepts, i.e., categories and elements. Dropping subcategories dramatically reduces the number of concepts in the new canvas to 13 (3 categories and 10 elements).

With regard to applicability and understandability, the Beta S-DSC highlights the concepts that have been considered key for the S-D mindset shift. As established by the evaluation of the Alpha S-DSC, the concepts of value-in-use and co-creation are key for shifting the mindset toward service dominance. Such concepts therefore become main categories in the tool and are positioned at the top and the center of the canvas, respectively. Second, academic jargon is removed from the Beta S-DSC, where possible, to be replaced by labels that are more familiar to practitioners. This 


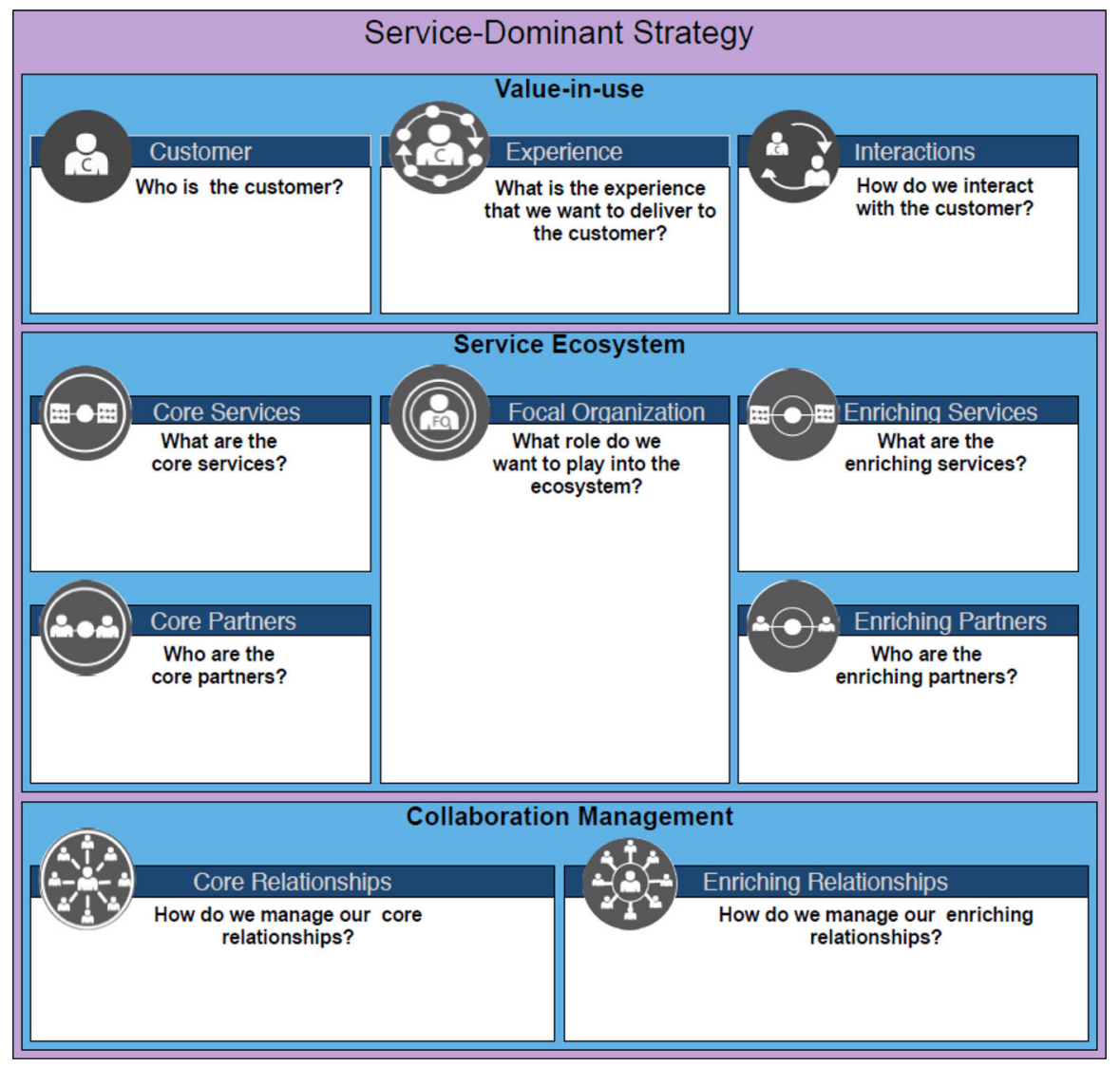

Fig. 4 Beta version of the S-DSC

is why the Endogenous and Exogenous labels become "core" and "enriching," respectively. For practitioners and users, the label "core" clearly identifies distinctive traits of their focal organization that are developed internally, whereas the label "enriching" clearly identifies opportunities available outside their focal organization to increase business value.

Within the value-in-use category, we further develop the elements by establishing a conceptual link between the elements of the S-D strategy and the elements considered by the BMC. Among the elements that appear in the BMC to facilitate strategic brainstorming, we select those related to the delivery of value propositions from the focal organization to the customer, i.e., "value proposition," "customer," and "channels." The element "value proposition" is reframed as Experience, where the value is co-created by use, not only to stress the need for a co-creation experience with customers, but also to avoid confusion with the Value-in-use label chosen for the category. The distribution "channels" are mechanisms for delivering the value proposition from the company to the customer. However, in S-D logic, the interactions with the customer are established in a bidirectional sense. Hence, we 
reframe this element of the BMC as Interactions in our tool, that is, a set of mechanisms through which the customer co-creates value with the organization. Besides creating a link with a management tool already in use by the users team, deriving elements using the BMC can be considered as a further conceptual bridge between the S-D strategy and traditional G-D frameworks driven by a marketoriented strategy.

Eventually, our ultimate goal is to guide users to formulate an S-D Strategy. Therefore, as with the Alpha S-DSC, we provide the key questions for facilitating the strategy formulation process. Note that, for the sake of consistency, the Beta S-DSC adopts the same "look and feel" convention as the Alpha version.

\subsection{Evaluation of the Beta version of the S-DSC}

The Beta S-DSC was evaluated in a working session with a group of seven executives (users) at CarLease, which lasted for $2 \mathrm{~h}$. The session was guided by one researcher and one practitioner. First, we briefly explained the goal of the session. After that, we asked the participants to design an S-D strategy using the Beta S-DSC. As we did for the intervention with the Alpha S-DSC, we concluded the session by administering the feedback survey, to evaluate the Beta S-DSC regarding the understandability, complexity, and bridging aspects, and by collecting the canvases filled in by the users to assess the applicability aspect.

During the intervention, users initially defined their customers as only people with a driving license, e.g., "everybody above 18". However, by using the Experience element of the Beta S-DSC, they were able to shift toward customers interested in the mobility service, e.g., "everybody that needs to go from A to B". This re-definition of the customer shows a clear shift from a G-D to the S-D way of formulating a strategy. The definition of the strategy as a position within the cocreation ecosystem helped the users to think about their company's role in providing a mobility experience.

More specifically, the bridging aspect was considered to have worked well, facilitated by the conceptual bridge established toward a subset of the concepts used in the BMC, and by the re-design of the S-DSC to embed strategy as a position of the focal company. The users engaged in defining the value-in-use of their S-D strategy, and they were able to position their focal company within the co-creation ecosystem.

Regarding the aspect of complexity of the Beta S-DSC, users did not specifically complain about the number of concepts to be understood, which was reduced from 24 in the Alpha S-DSC to 13 in the Beta S-DSC.

With regard to understandability, users clearly understood all the concepts presented in the Beta S-DSC. Such an understanding facilitated the S-D strategy formulation process through brainstorming based on the presented concepts.

Regarding the applicability, most elements in the Beta S-DSC were highly applicable. The users were able to fill in 9 out of the 10 elements in the canvas while designing their S-D strategy. The only concept with low applicability was Enriching relationships. Users had already brainstormed issues of collaboration management while considering the co-relationship element. When trying to brainstorm and fill in 
the Enriching relationships element, they were not able to come up with different mechanisms. Therefore, the element appeared redundant, rather than completely inapplicable, to support strategy formulation and communication.

Besides the four evaluation criteria discussed above, we also learned in the evaluation that designing an S-D strategy using the S-DSC aligns the interests of individual business units to the objective of the organization. Users were able to think about strategy in terms of the overall value-in-use for the customer, rather than focusing on business unit silos. Moreover, by specifically using the co-creation ecosystem elements, they were able to see how each individual business unit fits into the overall S-D strategy.

\section{Discussion}

In this section, we look back at the research process and outcomes presented in this paper with the aim of formalizing our learning and demonstrating the applicability of the resulting conceptual development and artifact to a generalizable class of problems. In doing so, we also reflect on the limitations of both the research process and the outcomes. This is the final step in the ADR research method adopted in this study (Sein et al. 2011).

The problem we faced is an instance of the dominant logic trap identified by Prahalad (2004). G-D logic, i.e., the dominant logic in strategy formulation adopted by most organizations, often prevents organizations from adopting the new mindset of S-D logic to explore new business models and opportunities. Few studies have focused on conceptualizing S-D logic at a strategic level (Karpen et al. 2012; Huff and Möslein 2009). These efforts, however, fail to deliver an integrated view of S-D strategy by accounting for the traditional resource-based, competence-based, and market-oriented views over business strategy.

In this paper, we identify a set of conceptual elements defining strategy from the S-D standpoint. The development of such a set of elements is grounded in the theory of traditional (Hunt and Derozier 2004) and S-D approaches (Lusch et al. 2007; Karpen et al. 2012; Järvesivu 2010) to strategy and on the theory of the dominant logic trap. In particular, the elements integrate previous research on S-D strategy using the traditional approaches as the bridging theory to overcome the G-D logic trap currently observed in organizations.

Hence, the conceptual elements of S-D strategy identified in our work are generalizable and applicable in practice beyond the scope of our case study in financial services. Our elements contribute to integrating the fragmented literature about S-D logic at a strategic level. While we exploit such elements to build a management tool for S-D strategy formulation and communication, i.e., the S-DSC, future research may use our elements for other purposes, such as defining metrics to measure S-D strategy fulfillment or maturity models to measure the alignment between the S-D principles and strategy definition and implementation.

Following the requirements of $\mathrm{ADR}$, this paper also contributes to practice by developing a management tool for formulating and communicating an S-D Strategy, i.e., the S-DSC. The design of this tool embeds the identification of the S-D strategy 
conceptual elements, and it has been improved through iteration by addressing the feedback received by practitioners and users. Although the tool adopts the canvas visual approach, it is clearly conceptually and practically distinguishable from the BMC tool, which still embeds a typical G-D logic, focusing on the identification of suppliers and customers in the value chain (Osterwalder and Pigneur 2010).

In our research, we have also identified a set of principles to effectively support the process of S-D strategy formulation and communication, which we summarize below.

Management tools to support the shift to the S-D logic in organizations should be developed by taking into account a clear bridging to management tools already in use by the organization. In our context, this translates into the need to bridge the elements of the S-D strategy in the Beta S-DSC to the concepts adopted by the $\mathrm{BMC}$, i.e., a tool already in use by the users of CarLease. This tool is largely adopted and the bridging we developed provides substantial generalizability to our S-DSC. We cannot assume, however, that bridging toward the concepts of a different existing management or decision support tool will be more effective in different organizational settings.

Although an S-D strategy focuses on value co-creation and networks of actors, a tool for formulating such strategy should still put the focal organization at the center of the stage. Decision makers tend to think of their company's strategy relative to the position of other partners and actors. In our specific case study, a tool that did not imply a central role for the focal organization, i.e., the Alpha S-DSC, initially puzzled the users. Confidence was restored by the Beta S-DSC, which restored the focal organization to a central position in the strategy formulation process.

In the development of management tools to support the shift to S-D strategy, academic jargon still represents an obstacle for people in industry. Therefore, the labels chosen and their positioning within the tool should be rigorously considered to avoid users deviating from the S-D mindset.

Managers, executives, and, specifically, decision makers prefer to work with simple tools, where simplicity is captured by (i) the use of the canvas approach with elements to be filled in using guiding questions and (ii) a relatively low number of concepts driving the brainstorming process. The number of concepts, i.e., elements and categories in our case, appearing in the tool should therefore be limited. New concepts should be introduced only when there is a clear request from practitioners to highlight important aspects of their business. In our tool, our process has led to the choice of 13 concepts as a reasonable number.

To sum up, we argue that our tool solves the general kinds of problems associated with designing and communicating an S-D Strategy. The generalizability of our tool, i.e., its suitability to industries other than the one represented by our case study, however, must be considered limited. The tool can be adjusted to different organizational settings if needed, particularly by considering the bridging aspect to the concepts adopted by different tools for the formulation of strategy and business models previously in use in the target organization or industry.

From a methodological standpoint, the ADR method adopted in this study presents intrinsic limitations that may limit the generalizability of the results. While ADR fosters collaboration between research and practice, it also requires the choice 
of an individual case study, which is dictated by the need for close collaboration between research and practice. As a result, the S-DSC has been developed and evaluated in the context of one specific industry and its applicability to different industries has not been fully demonstrated. Moreover, the iterative nature of artifact development in ADR does not give the users, i.e., executives of CarLease in our case, the opportunity to choose between different candidate designs for the artifact. In other words, the design of the artifact is dictated by the researchers and can improve only by iteratively addressing the feedback received during the evaluation. These limitations can be addressed by devising a more participative design approach, in which alternative mock-up designs are generated and users are involved in their evaluation.

As far as the output of our research is concerned, the S-DSC supports the process of formulating and communicating S-D strategy, but it does not guarantee the quality of the outcome of the process. That is, our tool guarantees that the strategy designed using this method embeds S-D logic, but it does not guarantee that such a strategy is effective and is the best possible for the focal organization. This is a typical issue with all artifacts supporting strategy formulation. An artifact such as the S-DSC adopted in a highly unstructured process, such as strategy formulation, leaves substantial discretion to the users. Moreover, strategy assessment can only be performed in the long term, and success also relies upon a set of exogenous factors, such as global economic momentum and political landscape, which are hard to control for when formulating strategy.

\section{Conclusions and future research}

This paper focuses on the issues of S-D strategy conceptualization, formulation, and communication. We first have identified a set of conceptual elements defining an S-D strategy by filtering and integrating the currently fragmented literature on S-D logic at a strategic level (Lusch et al. 2007; Karpen et al. 2012; Järvesivu 2010) through the lenses of traditional approaches to strategy (Hunt and Derozier 2004). The results of our conceptual development are embedded in the development of an artifact, i.e., the Service-Dominant Strategy Canvas (S-DSC), to formulate and communicate a S-D strategy. In supporting the formulation and communication of S-D strategy, the S-DSC represents an improvement compared to other tools, such as the BMC (Osterwalder and Pigneur 2010), which embeds the traditional G-D and value chain-based perspective over strategy.

Our research can be extended along several directions. First, we aim to use our tool in different industries. In this study, the tool has been used by practitioners in the mobility industry (the users at CarLease) and in the financial services industry (the practitioners at AssetFin). Experimenting with the adoption of the tool by practitioners in other industries will strengthen its generalizability in solving generic problems.

Second, future work should address the issue of S-D business model design. Organizations, in fact, need to translate S-D strategies into concrete business models, clearly identifying the partners in the value network, their roles, and related 
revenue and costs. Similarly to the strategic level analyzed by this paper, tools supporting business model design, like the BMC, are still grounded in the traditional G-D logic, taking a value chain approach to revenue generation. Our objective is to develop a new conceptualization of business models based on the S-D strategy and a related tool to facilitate the formulation and communication of the S-D business models.

Eventually, the strategy design process considered in this work is part of a more extensive framework about S-D business operationalization that we are developing. In this framework, strategy and business models control the design of business processes and the related IT infrastructure. In this context, we plan to work on an innovative approach to align strategy and business model design using serviceoriented enterprise architecture design. In doing so, we focus on the service-oriented design of the business processes fulfilling an S-D strategy within the framework specified by S-D business models.

Open Access This article is distributed under the terms of the Creative Commons Attribution 4.0 International License (http://creativecommons.org/licenses/by/4.0/), which permits unrestricted use, distribution, and reproduction in any medium, provided you give appropriate credit to the original author(s) and the source, provide a link to the Creative Commons license, and indicate if changes were made.

\section{Appendix}

See Table 7.

Table 7 Service-dominant statements from the literature

\begin{tabular}{|c|c|c|c|}
\hline $\begin{array}{ll}\text { Source } & \text { Service-dominant strategic } \\
& \text { statement (SS) }\end{array}$ & $\begin{array}{l}\text { Market } \\
\text { relationships }\end{array}$ & $\begin{array}{l}\text { Business } \\
\text { competences }\end{array}$ & $\begin{array}{l}\text { Business } \\
\text { resources }\end{array}$ \\
\hline \multicolumn{4}{|l|}{ Lusch et al. (2007) } \\
\hline $\begin{array}{l}\text { SS1- "competitive advantage is a function } \\
\text { of how one firm applies its operant } \\
\text { resources to meet the needs of the customer } \\
\text { relative to how another firm applies its } \\
\text { operant resources" }\end{array}$ & $x$ & $\checkmark$ & $\checkmark$ \\
\hline $\begin{array}{l}\text { SS2_- collaborative competence is a } \\
\text { primary determinant of a firms acquiring } \\
\text { the knowledge for competitive advantage" }\end{array}$ & $x$ & $\checkmark$ & $x$ \\
\hline $\begin{array}{l}\text { SS3- "the continued ascendance of } \\
\text { information technology with associated } \\
\text { decrease in communication and } \\
\text { computation costs, provides firms } \\
\text { opportunities for increased competitive } \\
\text { advantage through innovative } \\
\text { collaboration" }\end{array}$ & $x$ & $\checkmark$ & $\boldsymbol{\nu}$ \\
\hline $\begin{array}{l}\text { SS4-"firms gain competitive advantage } \\
\text { by engaging customers and value network } \\
\text { partners in co-creation and co-production } \\
\text { activities" }\end{array}$ & $x$ & $\checkmark$ & $\boldsymbol{\nu}$ \\
\hline
\end{tabular}


Table 7 continued

\begin{tabular}{|c|c|c|c|}
\hline $\begin{array}{ll}\text { Source } & \text { Service-dominant strategic } \\
& \text { statement (SS) }\end{array}$ & $\begin{array}{l}\text { Market } \\
\text { relationships }\end{array}$ & $\begin{array}{l}\text { Business } \\
\text { competences }\end{array}$ & $\begin{array}{l}\text { Business } \\
\text { resources }\end{array}$ \\
\hline $\begin{array}{l}\text { SS5- "understanding how the customer } \\
\text { uniquely integrates and experiences } \\
\text { service-related resources (both private and } \\
\text { public) is a source of competitive } \\
\text { advantage through innovation" }\end{array}$ & $x$ & $\boldsymbol{\sim}$ & $\boldsymbol{\sim}$ \\
\hline $\begin{array}{l}\text { SS6- "providing service co-production } \\
\text { opportunities and resources consistent with } \\
\text { the customer's desire level of involvement } \\
\text { leads to improve competitive advantage } \\
\text { through enhanced customer experience" }\end{array}$ & $x$ & $\checkmark$ & $x$ \\
\hline $\begin{array}{l}\text { SS7- "firms can compete more effectively } \\
\text { through the adoption of collaboratively } \\
\text { developed, risk-based pricing value } \\
\text { propositions. Appropriately shifting the } \\
\text { economic risk of either firm or customer } \\
\text { through co-created value propositions } \\
\text { increase competitive advantage" }\end{array}$ & $x$ & $\checkmark$ & $\boldsymbol{\sim}$ \\
\hline $\begin{array}{l}\text { SS8- "the value network member that is } \\
\text { the prime integrator is in a stronger } \\
\text { competitive position. The retailer is } \\
\text { generally in the best position to become } \\
\text { prime integrator" }\end{array}$ & $x$ & $\boldsymbol{\nu}$ & $\checkmark$ \\
\hline $\begin{array}{l}\text { SS9- "firms that treat their employees as } \\
\text { operant resources will be able to develop } \\
\text { more innovative knowledge and skills and } \\
\text { thus gain competitive advantage" }\end{array}$ & $x$ & $x$ & $\boldsymbol{V}$ \\
\hline \multicolumn{4}{|l|}{ Karpen et al. (2012) } \\
\hline $\begin{array}{l}\text { SS10_- "individuated interaction } \\
\text { capability—understanding individual } \\
\text { customers' service processes, contexts, and } \\
\text { desired outcomes" }\end{array}$ & $\checkmark$ & $\checkmark$ & $\boldsymbol{V}$ \\
\hline $\begin{array}{l}\text { SS11- "relational interaction capability- } \\
\text { enhancing the connection of social and } \\
\text { emotional links with customers in service } \\
\text { processes" }\end{array}$ & $\checkmark$ & $\checkmark$ & $\boldsymbol{V}$ \\
\hline $\begin{array}{l}\text { SS12_ “ethical interaction capability- } \\
\text { supporting fair and non opportunistic } \\
\text { customer service processes" }\end{array}$ & $\boldsymbol{\sim}$ & $x$ & $x$ \\
\hline $\begin{array}{l}\text { SS13_-empowered interaction } \\
\text { capability_enabling customers to shape } \\
\text { the nature and content of service } \\
\text { processes" }\end{array}$ & $\boldsymbol{V}$ & $x$ & $\boldsymbol{V}$ \\
\hline $\begin{array}{l}\text { SS14_ “developmental interaction } \\
\text { capability-assisting customers' own } \\
\text { knowledge and competence development } \\
\text { in service processes" }\end{array}$ & $\boldsymbol{\sim}$ & $x$ & $x$ \\
\hline $\begin{array}{l}\text { SS15-"concerted interaction capability- } \\
\text { facilitating coordinated and integrated } \\
\text { service processes that include customers" }\end{array}$ & $x$ & $\checkmark$ & $\boldsymbol{V}$ \\
\hline
\end{tabular}


Table 7 continued

\begin{tabular}{|c|c|c|c|}
\hline $\begin{array}{ll}\text { Source } & \text { Service-dominant strategic } \\
& \text { statement (SS) }\end{array}$ & $\begin{array}{l}\text { Market } \\
\text { relationships }\end{array}$ & $\begin{array}{l}\text { Business } \\
\text { competences }\end{array}$ & $\begin{array}{l}\text { Business } \\
\text { resources }\end{array}$ \\
\hline \multicolumn{4}{|l|}{ Järvesivu (2010) } \\
\hline $\begin{array}{l}\text { SS16- "flexible organizational boundaries } \\
\text { in which collaboration is encouraged by } \\
\text { minimizing the barriers for building large } \\
\text { networks of individuals and organizations } \\
\text { across boundaries" }\end{array}$ & $\checkmark$ & $x$ & $\boldsymbol{\nu}$ \\
\hline $\begin{array}{l}\text { SS17- "networked resource integration by } \\
\text { forming and maintaining strategic } \\
\text { partnerships that require the integration of } \\
\text { resources among all the actors involved" }\end{array}$ & $\checkmark$ & $\checkmark$ & $\checkmark$ \\
\hline $\begin{array}{l}\text { SS18- "value with end customers in which } \\
\text { the company and customers co-develop } \\
\text { offerings" }\end{array}$ & $x$ & $\checkmark$ & $x$ \\
\hline $\begin{array}{l}\text { SS19_-focus on value creating with the } \\
\text { objective of mutual benefits" }\end{array}$ & $\checkmark$ & $x$ & $x$ \\
\hline $\begin{array}{l}\text { SS20_- "a dialog between the company and } \\
\text { the market, where the innovation meets } \\
\text { demand" }\end{array}$ & $\checkmark$ & $x$ & $x$ \\
\hline $\begin{array}{l}\text { SS21- "market and customer knowledge } \\
\text { is shared and applied across all the } \\
\text { organization rather than a dedicated market } \\
\text { function" }\end{array}$ & $x$ & $\checkmark$ & $x$ \\
\hline $\begin{array}{l}\text { SS22- "holistic offerings that are part of } \\
\text { the usage context, where actors co-develop } \\
\text { offerings and co-create value" }\end{array}$ & $\checkmark$ & $x$ & $x$ \\
\hline
\end{tabular}

\section{References}

Avison DE, Lau F, Myers MD, Nielsen PA (1999) Action research. Commun ACM 42(1):94-97

Batini C, Cappiello C, Francalanci C, Maurino A (2009) Methodologies for data quality assessment and improvement. ACM Comput Surv 41(3):16

Bettis RA, Prahalad CK (1995) The dominant logic: retrospective and extension. Strateg Manag J 16(1):5-14

Coughlan P, Coghlan D (2002) Action research for operations management. Int J Oper Prod Manag 22(2):220-240

Fritscher B, Pigneur Y (2009) Supporting business model modelling: a compromise between creativity and constraints. In: Proceedings 8th international workshop on task models and diagrams for user interface design, Springer, pp. 28-43

Grönroos C, Gummerus J (2014) The service revolution and its marketing implications: service logic vs service-dominant logic. Manag Serv Qual 24(3):206-229

Hevner AR, March ST, Park J, Ram S (2004) Design science in information systems research. MIS Q 28(1):75-105

Huff A, Möslein K (2009) Framing research on service. In: Bergh D, Ketchen D (eds) Research methodology in strategy and management, vol 5. Oxford University, Oxford, pp 179-212

Hunt S, Derozier C (2004) The normative imperatives of business and marketing strategy: grounding strategy in resource-advantage theory. J Bus Ind Mark 19(1):5-22

Järvesivu P (2010) Constructing a service-dominant strategy: a practice-theoretical study of a start-up company. PhD thesis, Aalto University School of Economics 
Karpen I, Bove L (2008) Linking s-d logic and marketing practice: Toward a strategic service orientation. In: Ballantyne D, Aitken R, Williams J, Biggemann S (eds) Proceedings of the Otago Forum 2, pp. 213-237

Karpen I, Bove L, Luka B (2012) Linking service-dominant logic and strategic business practice: a conceptual model of a service-dominant orientation. J Serv Res 15(1):21-38

Karpen IO, Bove L, Lukas BA, Zyphurb MJ (2015) Service-dominant orientation: measurement and impact on performance outcomes. J Retail 91(1):89-108

Kowalkowski C (2011) Dynamics of value propositions: insights from service-dominant logic. Eur J Mark 45(1/2):277-294

Lusch RF, Vargo SL (2008) The service-dominant mindset. In: Hefley B, Murphy W (eds) Service science, management and engineering education for the 21st century, service science: research and innovations in the service economy, Springer, pp. 89-96

Lusch RF, Vargo SL (2014) Service-dominant logic: premises, perspectives, Possibilities. Cambridge University Press, Cambridge

Lusch RF, Vargo SL, O'Brien M (2007) Competing through service: insights from service-dominant logic. J Retail 83(1):5-18

McCarthy EJ (1960) Basic marketing — a managerial approach. Richard D. Irwin Inc., Homewood

Mintzberg H (1987) The strategy concept 1: five p's for strategy. University of California

Mont O (2002) Drivers and barriers for shifting towards more service-oriented businesses: analysis of the pss field and contributions from sweden. J Sustain Prod Des 2(3-4):89-103

Ng I, Parry G, Smith L, Maull R, Briscoe G (2012) Transitioning from a goods-dominant to a servicedominant logic: visualising the value proposition of Rolls-Royce. J Serv Manag 32(3):416-439

Okoli C, Pawlowski SD (2004) The Delphi method as a research tool: an example, design considerations and applications. Inf Manag 1(42):15-29

Osterwalder A, Pigneur Y (2002) An e-business model ontology for modeling e-business. In: Proceedings of 15th bled electronic commerce conference, pp. 75-91

Osterwalder A, Pigneur I (2010) Business model generation: a handbook for visionaries, game changers and challengers. Willey, New Jersey

Ostrom AL, Bitner MJ, Brown SW, Burkhard KA, Goul M, Smith-Daniels V, Demirkan H, Rabinovich E (2010) Moving forward and making a difference: research priorities for the science of service. J Serv Res 13(1):4-36

Peffers K, Tuunanen T, Gengler CE, Rossi M, Hui W, Virtanen V, Bragge J (2006) The design science research process: a model for producing and presenting information systems research. In: Proceedings 1st International conference on design science research in information systems and technology, pp. 83-106

Porter M (1985) Competitive strategy. Free Press, New York

Prahalad CK (2004) The blinders of dominant logic. Long Range Plan 37(2):171-179

Sein M, Henfridsson O, Purao S, Rossi M, Lindgren R (2011) Action design research. MIS Q 35(1):37-56

Skalen P, Gummerus J, von Koskull C, Magnusson PR (2014) Exploring value propositions and service innovation: a service-dominant logic study. J Acad Mark Sci 43(2):137-158

Smith L, Maull R, Ng IC (2014) Servitization and operations management: a service dominant-logic approach. Int J Oper Prod Manag 34(2):242-269

Spohrer J, Maglio PP (2008) The emergence of service science: toward systematic service innovations to accelerate co-creation of value. Prod Oper Manag 17(3):238-246

Stabell CB, Fjeldstad ØD (1998) Configuring value for competitive advantage: on chains, shops, and networks. Strateg Manag J 19(5):413-437

Vargo SL, Lusch RF (2004) Evolving to a new dominant logic for marketing. J Mark 68(1):1-17

Wise R, Baumgartner P (1999) Go downstream. Harv Bus Rev 77(5):133-141 